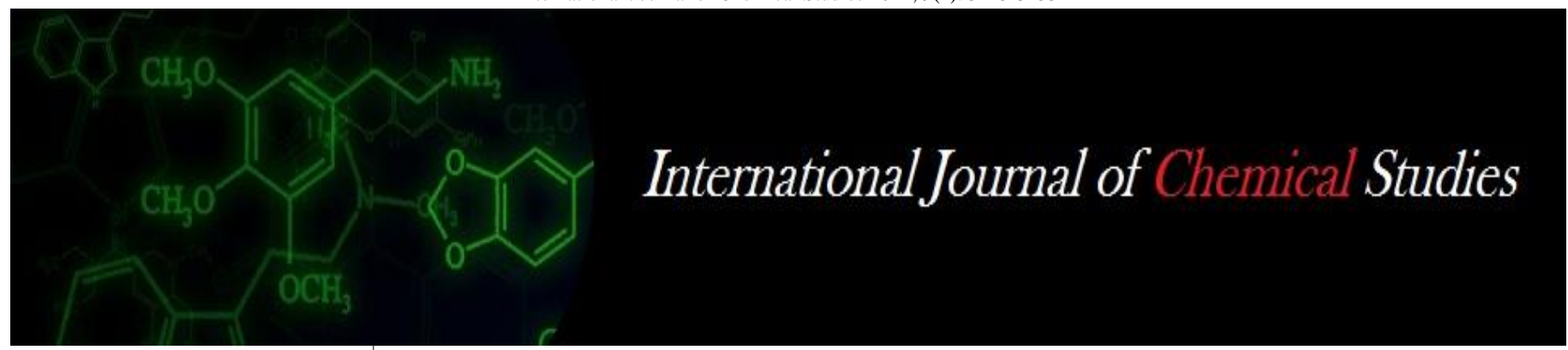

P-ISSN: 2349-8528

E-ISSN: 2321-4902

www.chemijournal.com

IJCS 2021; 9(1): 3145-3153

(C) 2021 IJCS

Received: $25-10-2020$

Accepted: 02-12-2020

\section{Neeraj Kumar}

Department of Agronomy,

College of Agriculture, Navsari

Agricultural University,

Bharuch, Gujarat, India

\section{BM Mote}

Directorate of Research Office,

Navsari Agricultural University,

Navsari, Gujarat, India

\section{Alok Srivastava}

Department of Statistics College

of Agriculture, Navsari

Agricultural University,

Bharuch, Gujarat, India

\section{DD Patel}

Department of Agronomy,

College of Agriculture, Navsari

Agricultural University,

Bharuch, Gujarat, India

\section{AL Chalodia}

Main Sorghum Research Station, Navsari Agricultural University,

Surat, Gujarat, India
Corresponding Author: Neeraj Kumar

Department of Agronomy, College of Agriculture, Navsari

Agricultural University,

Bharuch, Gujarat, India

\section{Rainy days analysis by using normal, binomial distribution and discrete probability for Navsari district of south Gujarat}

\author{
Neeraj Kumar, BM Mote, Alok Srivastava, DD Patel and AL Chalodia
}

DOI: https://doi.org/10.22271/chemi.2021.v9.i1ar.11712

\begin{abstract}
The standard weekly rainy days analysis of binomial distribution for monsoon season of Navsari on chisquare test on binomial distribution was found in SW 22 to 31,33 and SW 35 to 39 and post monsoon in standard week (SW) 41 to 44 shows significant. The result also reveals that the monsoon season SW 32 and 34 and post monsoon season SW 40, 45, 46 and 47 revealed non-significant result. Analysis reveals the rainfall is not equally distributed during SW $32,34,40,45,16$ and 47 , so that the test of binomial distribution is a good fit. Monsoon season rainfall data of Navsari reveals that the normal distribution at 10, 20 and $30 \%$ probability levels for the month of June, July, August and September shows the possibility of increasing rainy days occurrence. The Navsari districts during post monsoon season rainfall of months of October and November reveals decreasing tendency. The binomial distribution fit only those standard weeks in which rainfall is not equally distributed. From above results observed that the rainfall distribution is not equally distributed so test of binomial distribution at above given standard week is a good fit. The data also shows that, decreasing tendency in rainfall was observed in district.
\end{abstract}

Keywords: Rainy day analysis, discrete probability, Gaussian distributions, trend analysis

\section{Introduction}

It is well known that monsoon variability has a large impact on agricultural production and hence the economy in India. Naturally, considerable funds are allotted to research and development efforts towards identifying and adopting strategies that will allow us to cope better with the vagaries of the monsoon. These involve improvement in the skill of monsoon prediction, identification of the appropriate strategies for management of soil and water resources, appropriate choice of crops/ trees/fodder and farming strategies, etc. For estimation of the economic value of forecasts or the benefit of alternative strategies and several other purposes, a quantitative assessment is required. However, the system is complex with several factors besides the monsoon contributing to the variation in agricultural production and the gross domestic product (GDP). The Southwest monsoon is in full swing as it brings $75 \%$ of the rain to the country. The seasonal monsoon winds, blowing from the south-west and the northeast directions, are moisture-laden and bring in the yearly monsoon rains. These rains are critical to almost $60 \%$ of India's rain-fed agriculture and the timely arrival and adequacy of monsoon winds plays a vital role in our farming practices. These winds vary across seasons, across years and also across decades, and this variation is commonly known as monsoon variability. To adapt to the changing trends in monsoon variability, we first need to look at the situation of each region independently and propose adaptive measures applicable to those areas only. Around 70 per cent of the Indian population depends on farming and 58 per cent of the total employment in the country is through agriculture which contributes to around 18 per cent of the GDP. These numbers bring both, necessary responsibility and limitless risk to a large part of our population. As a tropical country with limited irrigation facility, the fate of the Kharif crops especially depends on the southwest Monsoon. The amount of rainfall in a specific area determines the type of crop that can adapt and grow to the natural factors affecting the region. Monsoon friendly crops with a high requirement of water like sugarcane, jute and paddy can easily be cultivated during summers, in areas with a high proximity for monsoons. Whereas, crops like wheat and barley require moderate temperature and water, and therefore can only be grown in winters. Kumar et al., (1992) ${ }^{[10]}$ examined the trends in the total 
precipitation during 1871-1984 and found increasing trends in the all most along the west coast of India and northwest India. Joshi et al., (2005) ${ }^{[7]}$ examined the trends in extreme rainfall indices for most of the extreme rainfall indices over the west coast and northwestern parts of Indian peninsula. However, very little work has been done on Gujarat state. Ray et al., (2009) ${ }^{[15]}$ studies climate variability and extreme weather events like cold wave and heat wave condition and heavy rainfall events in Gujarat and they recorded a significant steady increase in these events. Lunagaria et al., (2015) ${ }^{[12]}$ examined the rainfall patterns of Gujarat state, rainfall indices also showed no uniformity for any negative or positive trend over Gujarat. Total annual rainfall and extremely wet days were found to increase at more numbers of stations. As the rainfall is the parameter having very high variability, very few stations showed statistically significant trends. Thus, still there is ambiguity in the rainfall pattern for Gujarat state. In the context of climate change, it is pertinent to ascertain whether the characteristics of Indian monsoon are also changing. The Indian monsoon (June to September) rainfall is very crucial for the economic development, disaster management, hydrological planning for the country. However, increasing incidences of floods, droughts due to erratic weather, it's a time to explore ways of bringing a sustainable model of farming for our farmers and minimize dependency on monsoon of the monsoon rainfall.

The state receives rain under the influence of South west monsoon only during the four months from June to September. However, the onset, withdrawal and duration of monsoon are not uniform throughout the state. In south Gujarat, the monsoon commences from the middle of June and lasts up to end of October, while in north Gujarat a little latter and end by about the middle of September. In Saurashtra region, it commences from second week of June and lasts up to second week of September. The India Meteorological department views Gujarat state as two Subdivisions, Gujarat region and Saurashtra- Kutch region. The state's annual average rainfall is about $820 \mathrm{~mm}$ received in 30 rainy days. The annual average rainfall of Gujarat region is $970 \mathrm{~mm}$ received in 43 rainy days, while that of SaurashtraKutch region is only $580 \mathrm{~mm}$ received in an average of only 23 rainy days. The coefficient of variation $(\mathrm{CV} \%)$ of rainfall for Gujarat region is $23 \%$ and that of Saurashtra- Kutch is 35 percent. Considering Bharuch- Deesa line, the rainfall in the state decreases towards west of the line (Sahu, 2007) ${ }^{[16]}$.

\section{Materials and Methods}

The present study was carried out by using the 36 years (1980-2015) of daily meteorological data observed at Agrometeorological observatory, at Navsari, Gujarat $\left(20^{\circ} 57^{\prime} \mathrm{N}\right.$ latitude, $72^{\circ} 54^{\prime} \mathrm{E}$ longitude and $10 \mathrm{~m}$ ) and this station comes under south Gujarat heavy rainfall zone.

\subsection{Discrete probability (Binomial distribution)}

Probability distribution is a scientific way of dealing with uncertainty and making informed. In practice, probability distributions are applied in such diverse fields as actuarial science. The binomial distribution is a theoretical (regular) discrete probability distribution that is mainly used to calculate probabilities in experiments. This distribution arises in Bernoulli processes where in any trial; the event may or may not take place. The probability of occurrence of the event is the same from one trial to another. This distribution usually occurs while dealing with complementary events. A binomial distribution gives us the probabilities associated with independent, repeated Bernoulli trials. In a binomial distribution the probabilities of interest are those of receiving a certain number of successes, $r$, in $n$ independent trials each having only two possible outcomes and the same probability, p, of success (Lettenmaier et al., 1994) ${ }^{[11]}$.

Binomial distribution is used to study the probability of wet and dry period during the life cycle of the crop. The probability of rainy day is $\mathrm{p}$ and dry is $\mathrm{q}=1-\mathrm{p}$. If the probability of A (rainy day) is assumed to be independent of previous occurrence of $\mathrm{A}(\varphi)$ or a (dry day), the probability of $\mathrm{x}$ occurrences of $\mathrm{A}$ among $\mathrm{n}$ independent repetitions is

$\mathrm{px}=\mathrm{P}(\mathrm{X}=\mathrm{x})=\left(\begin{array}{l}n \\ x\end{array}\right) p^{x} q^{n-x}=\frac{\mathrm{n} !}{(\mathrm{n}-\mathrm{x}) ! \mathrm{x} !} p^{x} q^{n-x}$

\section{Where,}

$\mathrm{X}=0,1,2,------\mathrm{n}$

$\mathrm{x} !=1$ × 2 × 3 x ---------- $\mathrm{x}_{\mathrm{n}}$

$0 !=1$

The probability that there will be ' $r$ ' or fewer successes in ' $n$ ' independent trials is given by the cumulative distribution as:

$\mathrm{F}(\mathrm{r})=P(X \leq r)=\sum_{x=0}^{r}\left(\begin{array}{l}n \\ x\end{array}\right) p^{x} q^{n-x}$

Binomial distribution is also used to study the return period. A binomial is any pair of variables $(a \& b)$ raised to the given power

$(a+b)^{\mathrm{n}}$

$=a^{\mathrm{n}}+n a^{\mathrm{n}-1} \mathrm{~b}$

$+\frac{\mathrm{n} !}{2 !(\mathrm{n}-2) !} a^{\mathrm{n}-2} \mathrm{~b}^{2+----+} \frac{\mathrm{n} !}{(\mathrm{i}-\mathrm{l}) !(\mathrm{n}-\mathrm{i}+\mathrm{l}) !} a^{(\mathrm{n}-\mathrm{i}+\mathrm{l})} \mathrm{b}^{(\mathrm{i}-\mathrm{l})}$

$\mathrm{a}+\mathrm{b}=1($ or $100 \%)$

Each expansion can be used to calculate a series of probabilities for a sequence of years given by ' $n$ '.

\subsection{Gaussian distribution (Normal distribution)}

The normal distribution is the most widely known and used of all distributions. Normal distributions are extremely important because they occur so often in real applications and they play such an important role in methods of inferential statistics. The standard normal distribution is a special case of the normal distribution. It is the distribution that occurs when a normal random variable has a mean of zero and a standard deviation of one. The normal random variable of a standard normal distribution is called a standard score or a z-score. A normal distribution also is a fundamental mathematical assumption of many commonly used statistical techniques (Ben-Gai et al., 1998) ${ }^{[2]}$.

The normal distribution is the most important continues distribution in climatological analysis. Its frequency or probability density function is given by

$\mathrm{F}(\mathrm{x})=\frac{1}{\sigma \sqrt{2} \pi} \mathrm{e}^{-1 / 2\{\mathrm{x}-\mu / \sigma\} 2}$

Where

$\mu \quad=\quad$ Population mean

$\sigma \quad=\quad$ Population standard deviation

' $\mu$ ' is best estimated by $\overline{\mathrm{x}}$ and ' $\sigma$ ' by's'. There are obtained from the sample values by the relationship 


$$
\begin{array}{lll}
\overline{\mathrm{X}} & =\frac{\mathrm{l}}{\mathrm{n}} \sum_{0}^{\mathrm{n}} \mathrm{x} \\
\mathrm{S} & =\sqrt{\frac{\sum(\mathrm{X}-\overline{\mathrm{X}}) 2}{\mathrm{n}-1}}
\end{array}
$$

The normal distribution function cannot be expressed in terms of simple function, but must be evaluated by means of function expansion. Many tables of the normal distribution function and related function have been prepared using the variables.

$$
\mathrm{U}=\frac{\mathrm{x}-\mu}{\sigma}
$$

Where $\mu$ is called standardized variable. Using this variable, the distribution function becomes which can be converted to any desired normal distribution simply by varying ' $\mu$ ' and ' $\sigma$ '.

Thus a single normal table with augment' $t$ ', which is also a table of distribution with mean 0 and standard deviation unity, may be used to obtain the probabilities for any normal distribution.

Skewed distribution is obtained in rainfall climatological series for short period for which the mean rainfall is small. As the period increases, several shorter periods are added together. Hence, as the mean value gets larger, the sum of the several component periods approaches a normal distribution. The chi square statistic is defined as:

$$
\chi^{2}=\sum_{i} \frac{\left(O_{i}-E_{i}\right)^{2}}{E_{i}}
$$

Where, $\mathrm{O}_{\mathrm{i}}$ is the observed number of cases in category $\mathrm{i}$, and $E_{i}$ is the expected number of cases in category $i$. This chi square statistic is obtained by calculating the difference between the observed number of cases and the expected number of cases in each category. This difference is squared and divided by the expected number of cases in that category. These values are then added for all the categories, and the total is referred to as the chi squared value.

\section{Result and Discussion}

A common use of rainfall data is in the assessment of probability return periods of given rainfall at a given location. Such data can then be used in assessing flood discharges of given return through modelling or some empirical system and can thus be applied in schemes of flood alleviation forecasting and for the design of bridges and culverts. Navsari comes under south Gujarat heavy rainfall zone. South Gujarat receives 97 percent rainfall from South west monsoon (24 to 32 standard weeks) during the June to September. Normal rainfall of Navsari district is $1606 \mathrm{~mm}$ in 54 rainy days (Kumar et al., 2015) ${ }^{[9]}$. The analysis is carried out using the daily rainfall data of past years and the frequency distribution is calculated for monsoon (22 to 39 standard weeks) and post monsoon (40 to 47 standard weeks) seasons.

\subsection{Binomial distribution of Navsari district \\ 3.1.1. Monsoon season}

The standard weekly rainy days analysis of binomial distribution for monsoon season of Navsari district has been done on the basis of past 36 years rainfall data. The data reveals that highest value (1498.18) of chi-square test on binomial distribution was found in standard week (SW) 39. In
SW $39^{\text {th }}$ the number of rainy days $0,1,2,3,4,5,6$ and 7 were observed 19, 5, 2, 4, 2, 3, 0 and 1 times respectively. In SW $38^{\text {th }}$ rainy days $0,1,2,3,4,5,6$ and 7 were scrutinized $9,8,8$, $2,3,3,1$ and 2 times respectively with chi-square value (343.71). The Chi-square value 158.3799 was found in SW $37^{\text {th }}$, the rainy days come under this week $0,1,2,3,4,5,6$ and 7 were noticed $7,10,3,6,1,2,5$ and 2 times respectively. During SW week $37^{\text {th }}, 38^{\text {th }}$ and $39^{\text {th }}$ the calculated value is more than the table value and therefore the hypothesis acknowledged significant results at 5\% (14.07) and $10 \%$ (18.48) probability levels. It confirmed that the hypotheses of binomial distribution for $37^{\text {th }}, 38^{\text {th }}$ and $39^{\text {th }}$ standard weeks are not a good fit, table 1, i.e. result shows that the probability of weekly rainfall is well distributed in the weeks. Manikandan, et al., $2014^{[13]}$ had found that probability of weekly rainfall is well distributed. Similarly, at SW $22^{\text {nd }}$ to $39^{\text {th }}$ of monsoon season analysis divulged significant results at both $5 \%$ (14.07) and 10\% (18.48) probability levels the hypothesis of chi-square test for binomial distribution is not a good fit, except for $32^{\text {nd }}$ and $34^{\text {th }}$ standard weeks. In SW $34^{\text {th }}$ the number of rainy days $0,1,2,3,4,5,6$ and 7 were perceived $1,4,10,7,6,4,3$ and 1 times respectively with chisquare value (12.22). In $\mathrm{SW} 32^{\text {nd }}$ rainy days $0,1,2,3,4,5,6$ and 7 were discerned $0,1,3,11,6,5,7$ and 3 times respectively with chi-square value (12.21). It reveals that the calculated value is less than the table value and therefore the test affirmed non-significant results at 5\% (14.07) and $10 \%$ (18.48) probability levels. It concedes that the hypotheses of binomial distribution at $32^{\text {nd }}$ and $34^{\text {th }}$ standard weeks are a good fit table 1 . The result of both weeks indicates that rainfall distribution is not equal. Similar study was carried out by Sen and Eljadid, (1999) ${ }^{[18]}$ at Libya.

\subsubsection{Post -monsoon season}

The highest value (3920.33) of chi-square test on binomial distribution was found in SW 43. In SW 43 the number of rainy days $0,1,2,3,4,5,6$ and 7 were observed $34,1,0,0,1$, 0,0 and 0 times respectively. In SW 41 rainy days $0,1,2,3$, 4, 5, 6 and 7 were scrutinized 26, 5, 2, 1, 2, 0, 0 and 0 time respectively with chi-square value (79.93). Similarly, in SW 42 the chi-square value was found (33.19). In SW 42 the number of rainy days $0,1,2,3,4,5,6$ and 7 were discerned $31,4,0,1,0,0,0$ and 0 times respectively. The analysis reveals that during SW 44 the number of rainy days $0,1,2,3$, 4, 5, 6 and 7 were perceived 27, 4, 2, 3, 0, 0, 0 and 0 times respectively with chi-square value 26.1413. Chi-square analysis admits that during SW week $41^{\text {st }}, 42^{\text {nd }}, 43^{\text {rd }}$ and $44^{\text {th }}$ the calculated value is more than the table value and therefore the hypothesis affirms significant results at 5\% (14.07) and $10 \%$ (18.48) probability levels. It notifies that the hypotheses of binomial distribution at $41^{\text {st }}, 42^{\text {nd }}, 43^{\text {rd }}$ and $44^{\text {th }}$ standard weeks are not a good fit, i.e. result shows that probability of weekly rainfall well distributed in the weeks, table 2 .

The value (7.24) of chi-square test on binomial distribution was found in standard week SW 47. In SW 47 the number of rainy days $0,1,2,3,4,5,6$ and 7 were observed $33,2,1,0,0$, 0,0 and 0 time respectively. In SW 45 rainy days $0,1,2,3,4$, 5,6 and 7 were scrutinized 32,3,1,0,0,0,0 and 0 time respectively with chi-square value 5.70 . In SW 46 the number of rainy days $0,1,2,3,4,5,6$ and 7 were contemplated 31,4 , $1,0,0,0,0$ and 0 times respectively with chi-square value 4.86. The analysis reveals that during SW 40 the number of rainy days $0,1,2,3,4,5,6$ and 7 were espied 18, 12, 5, 1, 0, 0,0 and 0 times respectively with chi-square value (4.19). Chi-square analysis acknowledges that during SW week $40^{\text {th }}$, 
$45^{\text {th }}, 46^{\text {th }}$ and $47^{\text {th }}$, the calculated value is less than the table value and therefore showed non-significant results at $5 \%$ (14.07) and $10 \%$ (18.48) levels. It divulges that the hypotheses of binomial distribution at $40^{\text {th }}, 45^{\text {th }}, 46^{\text {th }}$ and $47^{\text {th }}$ standard weeks are a good fit, table 2 . The result revels that at $\mathrm{SW} 40^{\text {th }}, 45^{\text {th }}, 46^{\text {th }}$ and $47^{\text {th }}$ that rainfall distributions are not equal. The average weekly rainfall distribution indicates very high positive value of coefficient of correlation (Chand, et al., $2011)^{[3]}$. Similar result was reported by (Seetharam, 2010) ${ }^{[17]}$ and Probability distribution function has been fitted for the region estimation of climate change in extreme rainfall series of each station (Guhathakurta et al., 2005) ${ }^{[4]}$.

\subsection{Normal distribution}

The normal distribution analysis (10, 20 and 30\% probability levels) has been done on the basis of past 36 years of monsoon season rainfall data for Navsari district. Analysis reveals the possibility of occurrence for minimum rainy days as per normal distribution at 10,20 and 30\% probability levels for the month of June, are 11, 10 and 10 respectively. The normal rainy days in month of June are 8 . Normal distribution analysis at 10, 20 and $30 \%$ probability levels shows that the rainy days enrichment possibilities in terms of percentage are 39.25, 22.97 and 16.49 respectively. Correspondingly, the normal rainy days in a month of July are 18. The feasibility of incidences of minimum rainy days in July month at 10, 20 and $30 \%$ probability levels are 21,20 and 19 respectively. The Normal distribution analysis acknowledges that at 10, 20 and 30\% probability levels shows that the rainy days augmentation anticipation in terms of percentage are 28.24, 10.68 and 07.7 respectively. Equivalently, in August month the possibility of instance of minimum rainy days at 10,20 and $30 \%$ probability levels are 19, 17 and 17 respectively. The normal rainy days in a month of August are 16. The rainy days amplification probability at 10,20 and $30 \%$ probability levels in terms of percentage are $20.78,12.16$, and 08.73 respectively (table 3 ). Similarly for the month of September the possibility of appearance of minimum rainy days at 10,20 and $30 \%$ probability levels are 13,12 and 11 respectively.

Indistinguishably, the rainy days analysis of normal distribution at 10,20 and $30 \%$ probability levels for the whole monsoon season concedes that the possibility of existence of minimum rainy days are 55, 54 and 53 respectively. The normal rainy days at Navsari district for monsoon season are 52. Analysis of normal distribution at 10, 20 and $30 \%$ probability levels reveals that the rainy days augmentation possibilities in terms of percentage are 5.48, 2.90 and 1.87 respectively. Analogously, in post monsoon season the possibility of exigency of minimum rainy days are 5, 4 and 3 at 10, 20 and $30 \%$ probability levels respectively. Analysis of normal distribution at 10,20 and $30 \%$ probability levels divulges that the chances of rainy days augmentation prospects in terms of percentage are 151.28, 88.51 and 63.54 respectively, in table 3 .

\subsection{Trend in monsoon season}

3.3.1. June

The normal rainy days of June month are 8. The trend analysis showed significant increase in rainy days trend with an annual rate of 0.076 per year, fig. $1 \mathrm{a}$.

\subsubsection{July}

The normal rainy days of July month are 18. The trend analysis showed significant increase in rainy days with an annual rate of 0.006 per year, fig. $1 b$.

\subsubsection{August}

The normal rainy days of August month are 16. The trend analysis showed significant increase in rainy days trend with an annual rate of 0.010 per year, fig. $1 \mathrm{c}$.

\subsubsection{September}

The normal rainy days of September month are 10 . The trend analysis showed significant increase in rainy days trend with an annual rate of 0.097 per year, fig. $1 \mathrm{~d}$.

3.3.5. Monsoon season: The normal rainy days of monsoon season are 52. The trend analysis illustrated significant increase in rainy days with an annual rate of 0.190 per season, fig.1e. The similar result was found for annual rainfall at Navsari shows the increasing trend (Kumar et al., 2015-I) ${ }^{[9]}$, (Jaswal and Rao, 2010) ${ }^{[5]}$, (Jaswal et al., 2015) ${ }^{[6]}$ and (Basu et al., 2004) [1] the highest trend of monsoon rainfall anomalies of increasing nature is noticed. Kumar et al., (1992) [10] identified the areas having decreasing and increasing trends of monsoon rainfall. Guhathakurta (2005) ${ }^{[4]}$ used nine point Gaussian probability curve. It is clearly seen that no linear trend exists in this series. All India summer monsoon rainfall as well the rainfall during the four monsoon months does not show any significant trend.

\subsection{Trend in post monsoon season}

\subsubsection{October}

The normal rainy days of October month are 2. The trend analysis showed significant decrease in rainy days with an annual rate of -0.011 per year, fig. $2 \mathrm{a}$.

\subsubsection{November}

The normal rainy days of November month are 1 . The trend analysis showed significant increase in rainy days with an annual rate of 0.004 per year, fig. $2 b$. The similar result was found for annual rainfall at Navsari shows the increasing trend (Kumar et al., 2015-I) ${ }^{[9]}$.

3.4.3. Post monsoon: The normal rainy days of post monsoon season are 2 . The trend analysis showed significant decrease in rainy days with an annual rate of -0.007 per year, fig. $2 \mathrm{c}$. Similar result was found (Kumar et al., 2015-I) [9] and (Mohapatra, 2002) ${ }^{[14]}$ was found that rainfall rising trend during monsoon $\&$ falling trend during post monsoon.

Table 1: Rainy days analysis of binomial distribution for monsoon season for Navsari district

\begin{tabular}{|c|c|c|c|c|c|c|c|c|c|c|c|}
\hline Standard Weeks & $\mathbf{x}_{\mathbf{i}}$ & $\mathbf{n}_{\mathbf{i}}$ & $\mathbf{P}$ & $\mathbf{e}_{\mathbf{i}}$ & $\left(\mathbf{n}_{\mathrm{i}}-\mathbf{e}_{\mathrm{i}}\right)^{2} \mathbf{e}_{\mathrm{i}}$ & Standard Weeks & $\mathbf{x}_{\mathbf{i}}$ & $\mathbf{n}_{\mathbf{i}}$ & $\mathbf{P}$ & $\mathbf{e}_{\mathbf{i}}$ & $\left(n_{i}-e_{i}\right)^{2} e_{i}$ \\
\hline \multirow{7}{*}{22} & 0 & 27 & 0.61 & -3.66 & 0.44 & \multirow{7}{*}{23} & 0 & 19 & 0.29 & 4.57 & 1.45 \\
\hline & 1 & 4 & 0.31 & -11.53 & 8.56 & & 1 & 5 & 0.39 & -14.62 & 10.90 \\
\hline & 2 & 2 & 0.07 & -1.37 & 0.56 & & 2 & 5 & 0.23 & -6.44 & 3.62 \\
\hline & 3 & 3 & 0.01 & 2.59 & 16.56 & & 3 & 2 & 0.07 & -1.70 & 0.78 \\
\hline & 4 & 0 & 0.00 & -0.03 & 0.03 & & 4 & 5 & 0.01 & 4.28 & 25.45 \\
\hline & 5 & 0 & 0.00 & 0.00 & 0.00 & & 5 & 0 & 0.00 & -0.08 & 0.08 \\
\hline & 6 & 0 & 0.00 & 0.00 & 0.00 & & 6 & 0 & 0.00 & $\begin{array}{l}-0.01 \\
\end{array}$ & 0.01 \\
\hline
\end{tabular}




\begin{tabular}{|c|c|c|c|c|c|c|c|c|c|c|c|}
\hline & 7 & \begin{tabular}{|l|}
0 \\
\end{tabular} & 0.00 & 0.00 & 0.00 & & 7 & 0 & 0.00 & 0.00 & 0.00 \\
\hline & & & Tota & & 26.14 & & & & Tote & & 42.30 \\
\hline & 0 & 10 & 0.07 & 6.55 & 12.43 & & 0 & 10 & 0.07 & 6.69 & 13.50 \\
\hline & 1 & 6 & 0.22 & -5.23 & 2.44 & & 1 & 7 & 0.22 & -3.98 & 1.44 \\
\hline & 2 & 7 & 0.31 & -8.68 & 4.80 & & 2 & 5 & 0.31 & -10.61 & 7.21 \\
\hline & 3 & 2 & 0.24 & -10.15 & 8.48 & & 3 & 3 & 0.25 & -9.32 & 7.05 \\
\hline 24 & 4 & 4 & 0.11 & -1.65 & 0.48 & 25 & 4 & 4 & 0.12 & -1.84 & 0.58 \\
\hline & 5 & 5 & 0.03 & 3.42 & 7.43 & & 5 & 4 & 0.03 & 2.34 & 3.30 \\
\hline & 6 & 1 & 0.00 & 0.76 & 2.33 & & 6 & 2 & 0.01 & 1.74 & 11.53 \\
\hline & 7 & 1 & 0.00 & 0.98 & 59.56 & & 7 & 1 & 0.00 & 0.98 & 54.44 \\
\hline & & & Tota & & 97.96 & & & & Tots & & 99.06 \\
\hline & 0 & 8 & 0.02 & 6.79 & 38.32 & & 0 & 4 & 0.00 & 3.85 & 98.13 \\
\hline & 1 & 3 & 0.12 & -2.93 & 1.45 & & 1 & 3 & 0.03 & 1.64 & 1.96 \\
\hline & 2 & 6 & 0.25 & -6.50 & 3.38 & & 2 & 0 & 0.11 & -5.28 & 5.28 \\
\hline & 3 & 6 & 0.29 & -8.63 & 5.09 & & 3 & 4 & 0.23 & -7.37 & 4.78 \\
\hline 26 & 4 & 4 & 0.21 & -6.28 & 3.84 & 27 & 4 & 9 & 0.29 & -5.67 & 2.19 \\
\hline & 5 & 2 & 0.09 & -2.34 & 1.26 & & 5 & 9 & 0.23 & -2.37 & 0.49 \\
\hline & 6 & 4 & 0.02 & 2.98 & 8.77 & & 6 & 3 & 0.10 & -1.89 & 0.73 \\
\hline & 7 & 3 & 0.00 & 2.90 & 82.38 & & 7 & 4 & 0.02 & 3.10 & 10.64 \\
\hline & & & Tota & & 144.48 & & & & Tote & & 124.21 \\
\hline
\end{tabular}

\begin{tabular}{|c|c|c|c|c|c|c|c|c|c|c|}
\hline Standard Weeks & $\mathbf{x i}_{\mathbf{i}}$ & $\mathbf{n}_{\mathbf{i}}$ & $\mathbf{P}$ & $\mathbf{e}_{\mathbf{i}}$ & $\left(n_{i}-e_{i}\right)^{2} e_{i}$ & Standard Weeks & \begin{tabular}{|l|l}
$\mathbf{x}_{\mathbf{i}}$ & $\mathbf{n}$ \\
\end{tabular} & \begin{tabular}{l|l}
$\mathbf{n}_{\mathbf{i}}$ & $\mathbf{P}$ \\
\end{tabular} & $\mathbf{e}_{\mathbf{i}}$ & $\left(n_{i}-e_{i}\right)^{2} e_{i}$ \\
\hline \multirow[t]{9}{*}{ (2) } & 0 & 4 & 0.00 & 3.85 & 98.13 & \multirow[t]{9}{*}{ (2) } & \begin{tabular}{|l|l|}
0 & 0 \\
\end{tabular} & \begin{tabular}{l|l}
0 & 0.00 \\
\end{tabular} & -0.11 & 0.11 \\
\hline & 1 & 3 & 0.03 & 1.64 & 1.96 & & \begin{tabular}{l|l}
1 & 3 \\
\end{tabular} & 0.02 & 1.93 & 3.49 \\
\hline & 2 & 0 & 0.11 & -5.28 & 5.28 & & $2 \mid 5$ & 0.09 & 0.51 & 0.06 \\
\hline & 3 & 4 & 0.23 & -7.37 & 4.78 & & \begin{tabular}{l|l}
33 & 6 \\
\end{tabular} & 0.21 & -4.47 & 1.91 \\
\hline & 4 & 9 & 0.29 & -5.67 & 2.19 & & \begin{tabular}{l|l}
4 & 9
\end{tabular} & 0.29 & -5.66 & 2.18 \\
\hline & 5 & 9 & 0.23 & -2.37 & 0.49 & & \begin{tabular}{l|l}
5 & 4 \\
\end{tabular} & 0.25 & -8.31 & 5.61 \\
\hline & 6 & 3 & 0.10 & -1.89 & 0.73 & & \begin{tabular}{l|l}
6 & 3 \\
\end{tabular} & 0.11 & -2.75 & 1.31 \\
\hline & 7 & 4 & 0.02 & 3.10 & 10.64 & & \begin{tabular}{l|l}
7 & 6 \\
\end{tabular} & 0.02 & 4.85 & 20.48 \\
\hline & \multicolumn{4}{|c|}{ Total } & 124.21 & & \multicolumn{3}{|c|}{ Total } & 35.15 \\
\hline \multirow{9}{*}{30} & 0 & 3 & 0.00 & 2.90 & 82.38 & \multirow{8}{*}{31} & \begin{tabular}{l|l}
0 & 2 \\
\end{tabular} & \begin{tabular}{|l|l|}
2 & 0.00 \\
\end{tabular} & 1.85 & 22.64 \\
\hline & 1 & 3 & 0.02 & 1.98 & 3.88 & & \begin{tabular}{l|l}
15 \\
1
\end{tabular} & \begin{tabular}{|l|l|}
5 & 0.03 \\
\end{tabular} & 3.64 & 9.69 \\
\hline & 2 & 3 & 0.09 & -1.34 & 0.41 & & \begin{tabular}{|l|l|}
2 & 4 \\
\end{tabular} & 0.11 & -1.28 & 0.31 \\
\hline & 3 & 5 & 0.21 & -5.28 & 2.71 & & \begin{tabular}{|l|l|}
3 & 3 \\
\end{tabular} & 0.23 & -8.37 & 6.16 \\
\hline & 4 & 5 & 0.29 & -9.63 & 6.34 & & \begin{tabular}{l|l}
4 & 6
\end{tabular} & 0.29 & -8.67 & 5.13 \\
\hline & 5 & 4 & 0.25 & -8.50 & 5.78 & & \begin{tabular}{l|l}
5 & 4
\end{tabular} & 0.23 & -7.37 & 4.77 \\
\hline & 6 & 7 & 0.12 & 1.07 & 0.19 & & \begin{tabular}{l|l}
6 & 8
\end{tabular} & 0.10 & 3.11 & 1.98 \\
\hline & 7 & 6 & 0.02 & 4.79 & 19.08 & & \begin{tabular}{|l|l}
7 & 4 \\
\end{tabular} & 0.02 & 3.10 & 10.64 \\
\hline & \multicolumn{4}{|c|}{ Total } & 120.77 & \multicolumn{4}{|c|}{ Total } & 61.32 \\
\hline \multirow{9}{*}{32} & 0 & 0 & 0.00 & -0.08 & 0.08 & \multirow{9}{*}{33} & \begin{tabular}{l|l}
0 & 3 \\
\end{tabular} & 0.01 & 2.33 & 8.17 \\
\hline & 1 & 1 & 0.02 & 0.18 & 0.04 & & 16 & 0.08 & 2.02 & 1.02 \\
\hline & 2 & 3 & 0.08 & -0.76 & 0.15 & & \begin{tabular}{l|l}
2 & 3 \\
\end{tabular} & 0.20 & -7.19 & 5.07 \\
\hline & 3 & 11 & 0.19 & 1.48 & 0.23 & & 39 & 0.29 & -5.48 & 2.07 \\
\hline & 4 & 6 & 0.29 & -8.47 & 4.96 & & \begin{tabular}{|l|l}
4 & 5 \\
\end{tabular} & 0.25 & -7.35 & 4.37 \\
\hline & 5 & 5 & 0.26 & -8.20 & 5.09 & & \begin{tabular}{|l|l}
5 & 4 \\
\end{tabular} & 0.13 & -2.32 & 0.85 \\
\hline & 6 & 7 & 0.13 & 0.31 & 0.01 & & \begin{tabular}{|l|l|}
6 & 5 \\
\end{tabular} & 0.04 & 3.20 & 5.71 \\
\hline & 7 & 3 & 0.03 & 1.55 & 1.65 & & \begin{tabular}{|l|l|}
7 & 1 \\
\end{tabular} & $\begin{array}{ll}1 & 0.00\end{array}$ & 0.78 & 2.79 \\
\hline & \multicolumn{4}{|c|}{ Total } & 12.22 & & \multicolumn{3}{|c|}{\begin{tabular}{|c|} 
Total \\
\end{tabular}} & 30.05 \\
\hline
\end{tabular}

\begin{tabular}{|c|c|c|c|c|c|c|c|c|c|c|c|}
\hline Standard Weeks & $\mathbf{x}_{\mathbf{i}}$ & $\mathbf{n}_{\mathbf{i}}$ & $\mathbf{P}$ & $\mathbf{e}_{\mathbf{i}}$ & $\left(n_{i}-e_{i}\right)^{2} \mathbf{e}_{i}$ & Standard Weeks & $\mathbf{x}_{\mathbf{i}}$ & $\mathbf{n}_{\mathbf{i}}$ & $\mathbf{P}$ & $\mathbf{e}_{\mathbf{i}}$ & $\left(n_{i}-e_{i}\right)^{2} e_{i}$ \\
\hline \multirow[t]{9}{*}{ 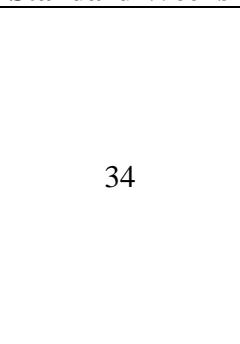 } & 0 & 1 & 0.01 & 0.26 & 0.09 & \multirow[t]{9}{*}{ 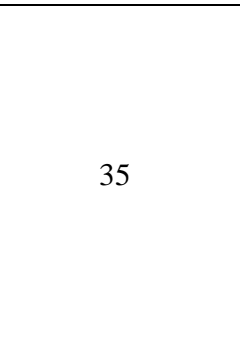 } & 0 & 7 & 0.03 & 5.74 & 26.05 \\
\hline & 1 & 4 & 0.09 & -0.27 & 0.02 & & 1 & 3 & 0.12 & -3.11 & 1.58 \\
\hline & 2 & 10 & 0.21 & -0.58 & 0.03 & & 2 & 8 & 0.25 & -4.68 & 1.73 \\
\hline & 3 & 7 & 0.29 & -7.57 & 3.93 & & 3 & 3 & 0.29 & -11.60 & 9.22 \\
\hline & 4 & 6 & 0.24 & -6.04 & 3.03 & & 4 & 5 & 0.20 & -5.10 & 2.57 \\
\hline & 5 & 4 & 0.12 & -1.97 & 0.65 & & 5 & 6 & 0.08 & 1.81 & 0.78 \\
\hline & 6 & 3 & 0.03 & 1.36 & 1.12 & & 6 & 3 & 0.02 & 2.04 & 4.29 \\
\hline & 7 & 1 & 0.00 & 0.81 & 3.35 & & 7 & 1 & 0.00 & 0.90 & 8.59 \\
\hline & \multicolumn{4}{|c|}{ Total } & 12.22 & & \multicolumn{4}{|c|}{ Total } & 54.82 \\
\hline \multirow{8}{*}{36} & 0 & 4 & 0.02 & 3.05 & 9.84 & \multirow{8}{*}{37} & 0 & 7 & 0.04 & 4.92 & 11.64 \\
\hline & 1 & 7 & 0.10 & 1.95 & 0.75 & & 1 & 10 & 0.17 & 1.63 & 0.32 \\
\hline & 2 & 7 & 0.23 & -4.56 & 1.80 & & 2 & 3 & 0.29 & -11.44 & 9.06 \\
\hline & 3 & 3 & 0.29 & -11.68 & 9.30 & & 3 & 6 & 0.28 & -7.84 & 4.44 \\
\hline & 4 & 4 & 0.22 & -7.19 & 4.62 & & 4 & 1 & 0.16 & -6.96 & 6.08 \\
\hline & 5 & 5 & 0.10 & -0.12 & 0.00 & & 5 & 2 & 0.05 & -0.75 & 0.20 \\
\hline & 6 & 4 & 0.03 & 2.70 & 5.60 & & 6 & 5 & 0.01 & 4.47 & 38.04 \\
\hline & 7 & 2 & 0.00 & 1.86 & 24.38 & & \begin{tabular}{|l|}
7 \\
\end{tabular} & 2 & 0.00 & 1.96 & 88.59 \\
\hline
\end{tabular}




\begin{tabular}{|c|c|c|c|c|c|c|c|c|c|c|c|}
\hline & \multicolumn{4}{|c|}{ Total } & 56.29 & & \multicolumn{4}{|c|}{ Total } & 158.38 \\
\hline \multirow{9}{*}{38} & 0 & 9 & 0.08 & 5.11 & 6.69 & \multirow{9}{*}{39} & 0 & 19 & 0.21 & 8.73 & 7.42 \\
\hline & 1 & 8 & 0.24 & -3.99 & 1.33 & & 1 & 5 & 0.36 & -13.24 & 9.61 \\
\hline & 2 & 8 & 0.32 & -7.83 & 3.88 & & 2 & 2 & 0.28 & -11.88 & 10.17 \\
\hline & 3 & 2 & 0.23 & -9.61 & 7.96 & & 3 & 4 & 0.12 & -1.87 & 0.60 \\
\hline & 4 & 3 & 0.10 & -2.11 & 0.87 & & 4 & 2 & 0.03 & 0.51 & 0.17 \\
\hline & 5 & 3 & 0.03 & 1.65 & 2.02 & & 5 & 3 & 0.00 & 2.77 & 33.91 \\
\hline & 6 & 1 & 0.00 & 0.80 & 3.25 & & 6 & 0 & 0.00 & -0.02 & 0.02 \\
\hline & 7 & 2 & 0.00 & 1.99 & 317.72 & & \begin{tabular}{|l|}
7 \\
\end{tabular} & 1 & 0.00 & 1.00 & 1436.28 \\
\hline & \multicolumn{4}{|c|}{ Total } & 343.72 & & \multicolumn{4}{|c|}{ Total } & 1498.18 \\
\hline
\end{tabular}

Table 2: Rainy days analysis of binomial distribution for post monsoon season for Navsari district

\begin{tabular}{|c|c|c|c|c|c|c|c|c|c|c|c|}
\hline Standard Weeks & $\mathbf{x}_{\mathbf{i}}$ & $\mathbf{n}_{\mathbf{i}}$ & $\mathbf{P}$ & $\mathbf{e}_{\mathbf{i}}$ & $\left(n_{i}-e_{i}\right)^{2} e_{i}$ & Standard Weeks & $\mathbf{x i}_{\mathbf{i}}$ & $\mathbf{n}_{\mathbf{i}}$ & $\mathbf{P}$ & $\mathbf{e}_{\mathbf{i}}$ & $\left(n_{i}-e_{i}\right)^{2} e_{i}$ \\
\hline \multirow[t]{9}{*}{ (2) } & 0 & 18 & 0.48 & -6.06 & 1.53 & \multirow[t]{9}{*}{ 20 } & 0 & 26 & 0.56 & -2.03 & 0.15 \\
\hline & 1 & 12 & 0.37 & -6.55 & 2.31 & & 1 & 5 & 0.34 & -11.91 & 8.39 \\
\hline & 2 & 5 & 0.12 & -1.13 & 0.21 & & 2 & 2 & 0.09 & -2.37 & 1.29 \\
\hline & 3 & 1 & 0.02 & -0.13 & 0.01 & & 3 & 1 & 0.01 & 0.37 & 0.22 \\
\hline & 4 & 0 & 0.00 & -0.12 & 0.12 & & 4 & 2 & 0.00 & 1.95 & 69.89 \\
\hline & 5 & 0 & 0.00 & -0.01 & 0.01 & & 5 & 0 & 0.00 & 0.00 & 0.00 \\
\hline & 6 & 0 & 0.00 & 0.00 & 0.00 & & 6 & 0 & 0.00 & 0.00 & 0.00 \\
\hline & 7 & \begin{tabular}{|l|l|}
0 \\
\end{tabular} & 0.00 & 0.00 & 0.00 & & 7 & 0 & 0.00 & 0.00 & 0.00 \\
\hline & \multicolumn{4}{|c|}{ Total } & 4.20 & & \multicolumn{4}{|c|}{ Total } & 79.93 \\
\hline \multirow{9}{*}{42} & 0 & 31 & 0.82 & -10.05 & 2.46 & \multirow{9}{*}{43} & 0 & 34 & 0.87 & -9.46 & 2.06 \\
\hline & 1 & 4 & 0.16 & -4.21 & 2.16 & & 1 & 1 & 0.12 & -5.16 & 4.32 \\
\hline & 2 & 0 & 0.01 & -0.70 & 0.70 & & 2 & 0 & 0.01 & -0.37 & 0.37 \\
\hline & 3 & 1 & 0.00 & 0.97 & 27.87 & & 3 & 0 & 0.00 & -0.01 & 0.01 \\
\hline & 4 & 0 & 0.00 & 0.00 & 0.00 & & 4 & 1 & 0.00 & 1.00 & 3913.57 \\
\hline & 5 & \begin{tabular}{|l|}
0 \\
\end{tabular} & 0.00 & 0.00 & 0.00 & & 5 & 0 & 0.00 & 0.00 & 0.00 \\
\hline & 6 & 0 & 0.00 & 0.00 & 0.00 & & 6 & 0 & 0.00 & 0.00 & 0.00 \\
\hline & 7 & \begin{tabular}{|l|l|}
0 & \\
\end{tabular} & 0.00 & 0.00 & 0.00 & & 7 & 0 & 0.00 & 0.00 & 0.00 \\
\hline & \multicolumn{4}{|c|}{ Total } & 33.20 & & \multicolumn{4}{|c|}{ Total } & 3920.33 \\
\hline \multirow{9}{*}{44} & 0 & 27 & 0.61 & -3.66 & 0.44 & \multirow{9}{*}{45} & 0 & 32 & 0.87 & -11.46 & 3.02 \\
\hline & 1 & 4 & 0.31 & -11.53 & 8.56 & & 1 & 3 & 0.12 & -3.16 & 1.62 \\
\hline & 2 & 2 & 0.07 & -1.37 & 0.56 & & 2 & 1 & 0.01 & 0.63 & 1.05 \\
\hline & 3 & \begin{tabular}{|l|}
3 \\
\end{tabular} & 0.01 & 2.59 & 16.56 & & \begin{tabular}{|l|}
3 \\
\end{tabular} & 0 & 0.00 & -0.01 & 0.01 \\
\hline & 4 & \begin{tabular}{|l|}
0 \\
\end{tabular} & 0.00 & -0.03 & 0.03 & & 4 & 0 & 0.00 & 0.00 & 0.00 \\
\hline & 5 & \begin{tabular}{|l|}
0 \\
\end{tabular} & 0.00 & 0.00 & 0.00 & & 5 & 0 & 0.00 & 0.00 & 0.00 \\
\hline & 6 & \begin{tabular}{|l|}
0 \\
\end{tabular} & 0.00 & 0.00 & 0.00 & & 6 & 0 & 0.00 & 0.00 & 0.00 \\
\hline & 7 & \begin{tabular}{|l|}
0 \\
\end{tabular} & 0.00 & 0.00 & 0.00 & & 7 & 0 & 0.00 & 0.00 & 0.00 \\
\hline & \multicolumn{4}{|c|}{ Total } & 26.14 & & \multicolumn{4}{|c|}{ Total } & 5.70 \\
\hline
\end{tabular}

Shows significance $\mathrm{P}=0.01(<18.48)$ and $\mathrm{P}=0.05(<14.07)$ and hypothesis accepted

\begin{tabular}{|c|c|c|c|c|c|c|c|c|c|c|c|}
\hline Standard Weeks & $\mathbf{x}_{\mathbf{i}}$ & $\mathbf{n}_{\mathbf{i}}$ & $\mathbf{P}$ & $\mathbf{e}_{\mathbf{i}}$ & $\left(n_{i}-e_{i}\right)^{2} e_{i}$ & Standard Weeks & $\mathbf{x}_{\mathbf{i}}$ & $\mathbf{n}_{\mathbf{i}}$ & $\mathbf{P}$ & $\mathbf{e}_{\mathbf{i}}$ & $\left(\mathbf{n}_{\mathrm{i}}-\mathbf{e}_{\mathrm{i}}\right)^{2} \mathbf{e}_{\mathrm{i}}$ \\
\hline \multirow[t]{9}{*}{ tros } & \begin{tabular}{l|l}
0 & 3 \\
\end{tabular} & 31 & 0.84 & -11.24 & 2.99 & \multirow[t]{9}{*}{ 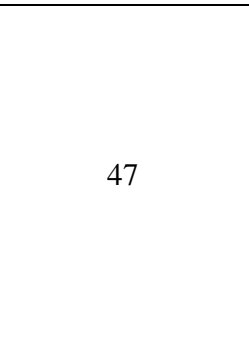 } & 0 & 33 & 0.89 & -11.70 & 3.06 \\
\hline & 1 & 4 & 0.14 & -3.21 & 1.43 & & 1 & 2 & 0.10 & -3.05 & 1.84 \\
\hline & 2 & 1 & 0.01 & 0.47 & 0.42 & & 2 & 1 & 0.00 & 0.76 & 2.34 \\
\hline & \begin{tabular}{l|l}
3 \\
\end{tabular} & 0 & 0.00 & -0.02 & 0.02 & & 3 & 0 & 0.00 & -0.01 & 0.01 \\
\hline & 4 & 0 & 0.00 & 0.00 & 0.00 & & 4 & 0 & 0.00 & 0.00 & 0.00 \\
\hline & 5 & 0 & 0.00 & 0.00 & 0.00 & & 5 & 0 & 0.00 & 0.00 & 0.00 \\
\hline & 6 & 0 & 0.00 & 0.00 & 0.00 & & 6 & 0 & 0.00 & 0.00 & 0.00 \\
\hline & 7 & 0 & 0.00 & 0.00 & 0.00 & & 7 & 0 & 0.00 & 0.00 & 0.00 \\
\hline & & & Tota & & 4.87 & & & & Tota & & 7.25 \\
\hline
\end{tabular}

Table 3: Analysis for normal distribution of occurrence of rainy days at different probability levels against normal for Navsari district

\begin{tabular}{|c|c|c|c|c|c|c|c|c|}
\hline \multirow{2}{*}{ Probability Levels (X) } & \multicolumn{7}{|c|}{ Months } & \multicolumn{2}{c|}{ Seasons } \\
\cline { 2 - 10 } & June & July & August & September & October & November & Monsoon Post monsoon \\
\hline 0.10 & 11 & 21 & 19 & 13 & 5 & 4 & 55 & 5 \\
\hline Different percentage with normal rainy days & 39.25 & 18.24 & 20.78 & 32.29 & 194.30 & 271.06 & 5.48 & 151.28 \\
\hline 0.20 & 10 & 20 & 17 & 12 & 4 & 2 & 54 & 4 \\
\hline Different percentage with normal rainy days & 22.97 & 10.68 & 12.16 & 18.90 & 113.71 & 136.74 & 2.90 & 88.51 \\
\hline 0.30 & 10 & 19 & 17 & 11 & 3 & 2 & 53 & 3 \\
\hline Different percentage with normal rainy days & 16.49 & 07.67 & 08.73 & 13.57 & 81.65 & 83.30 & 1.87 & 63.54 \\
\hline Normal rainy days & 8 & 18 & 16 & 10 & 2 & 1 & 52 & 2 \\
\hline
\end{tabular}



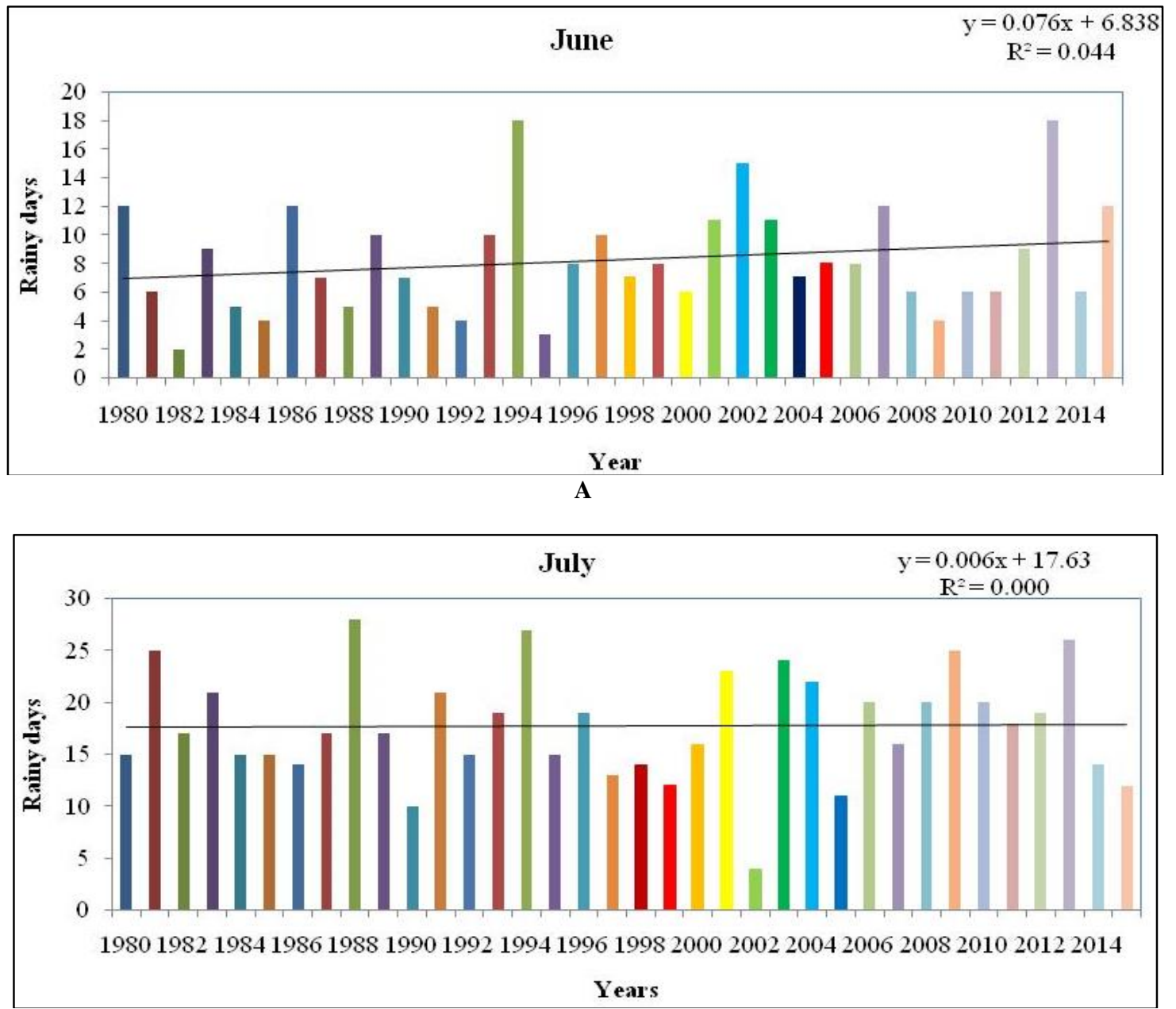

B.

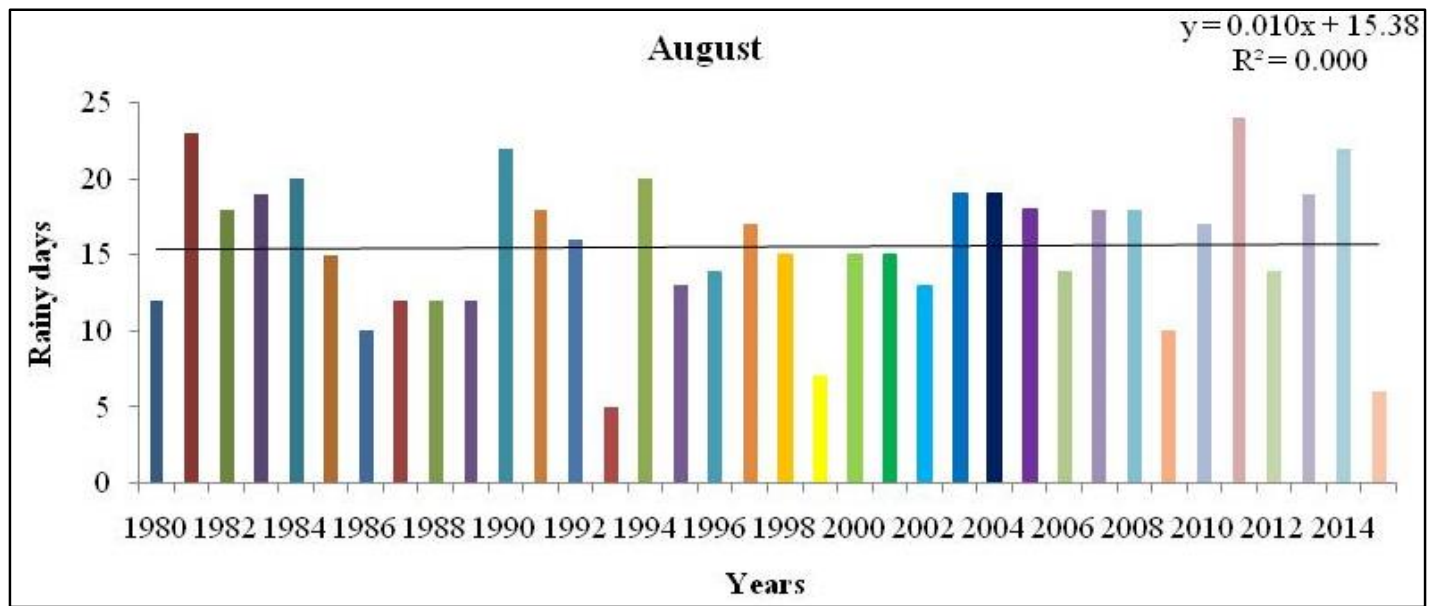

C.

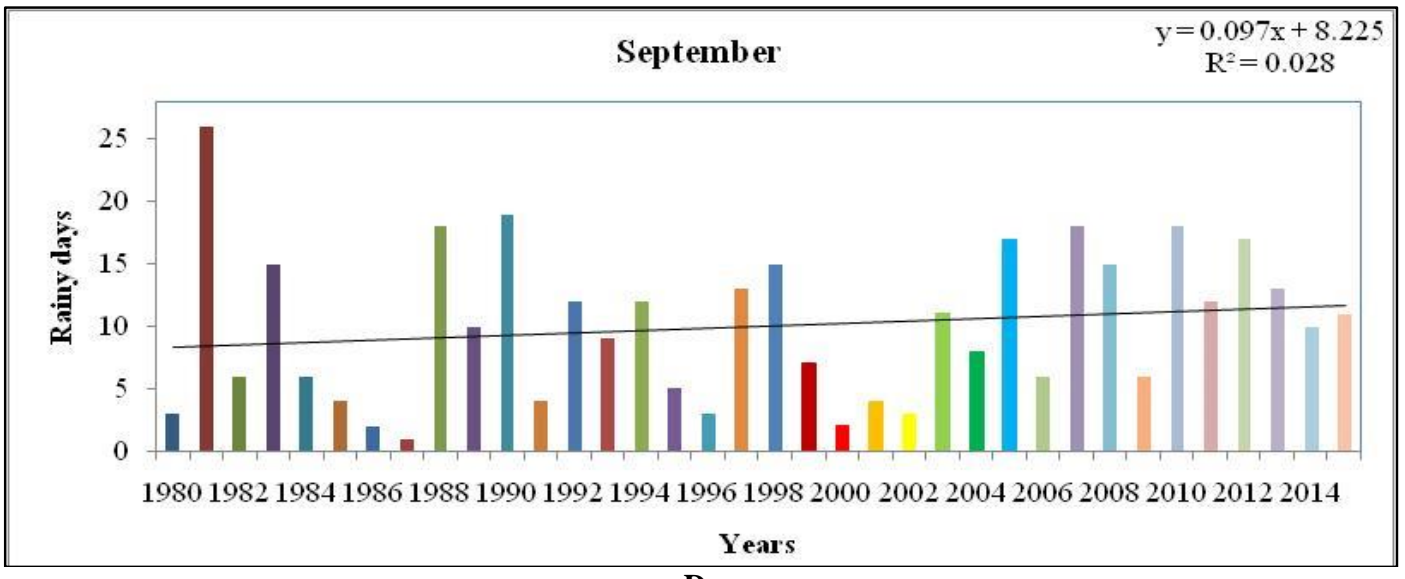

D.

3151 


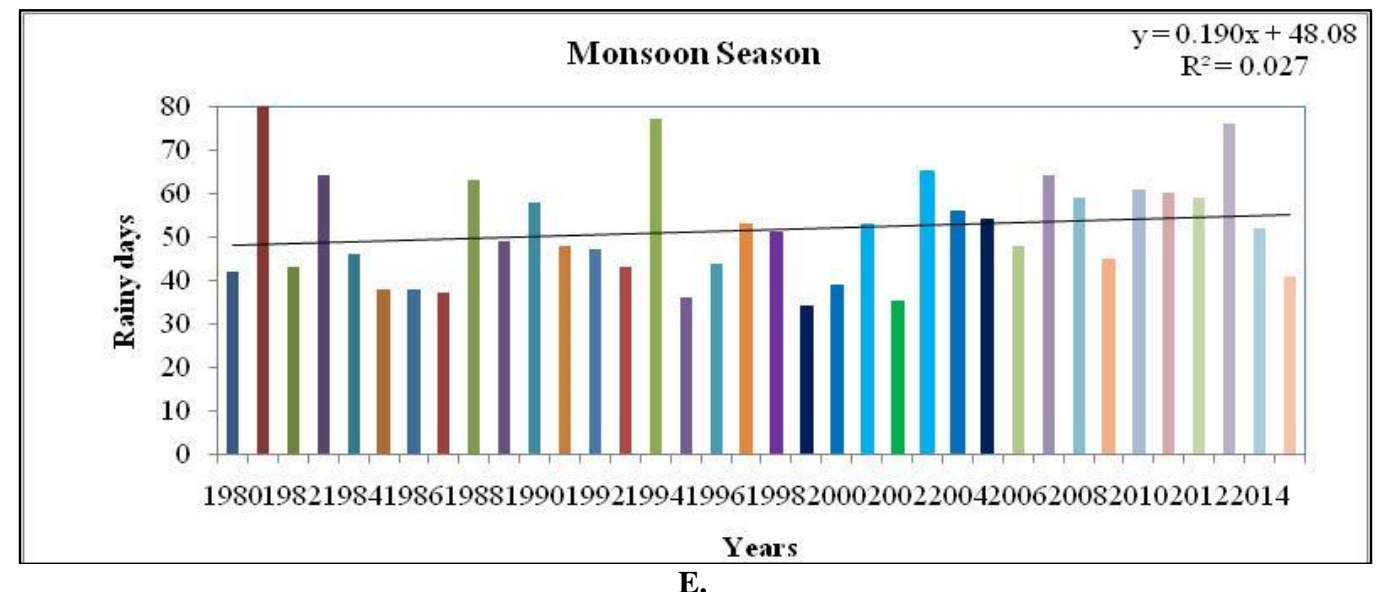

Fig 1a-e: Monthly and monsoon season variability and trend at Navsari district

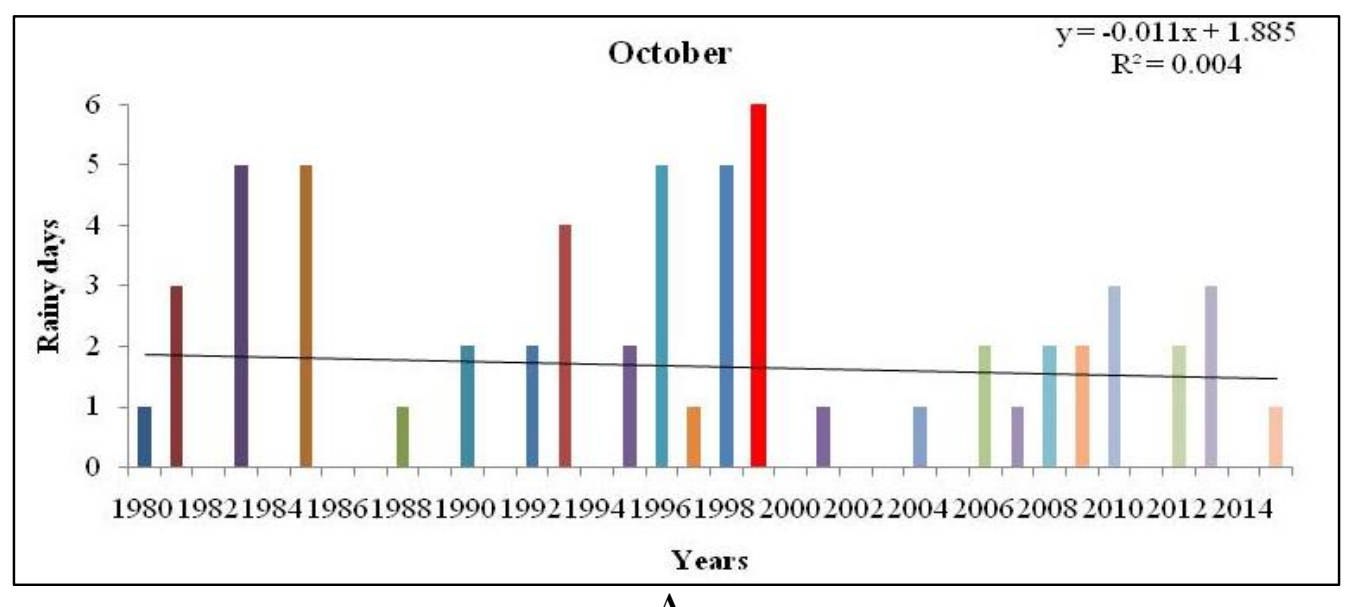

A.

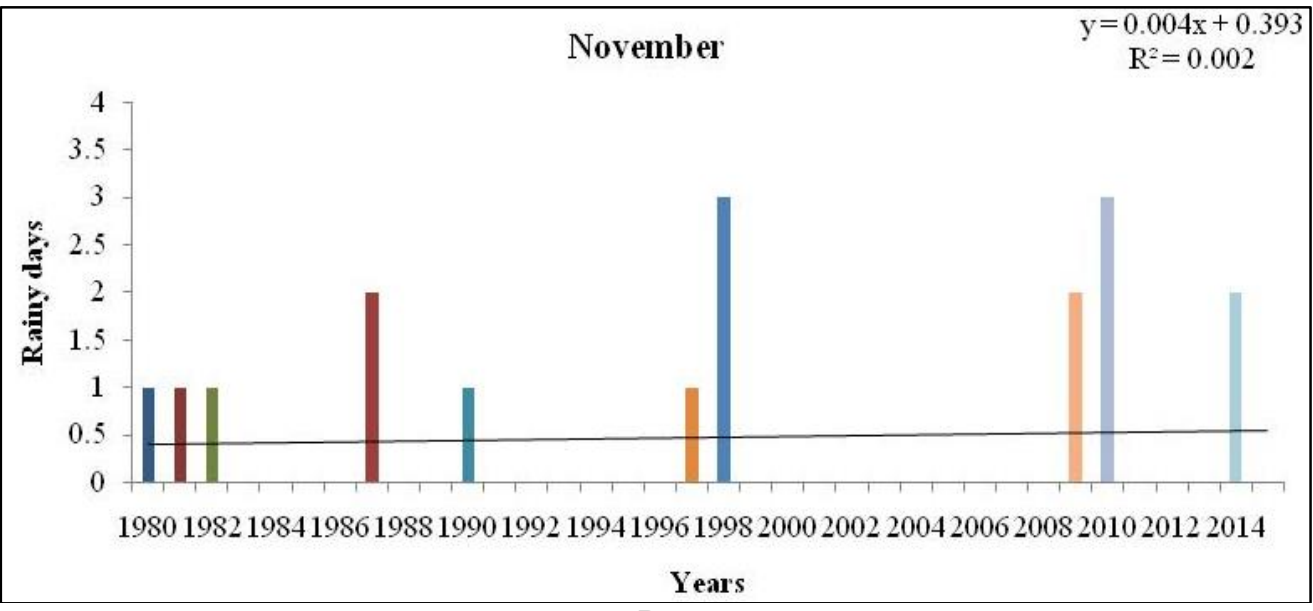

B.

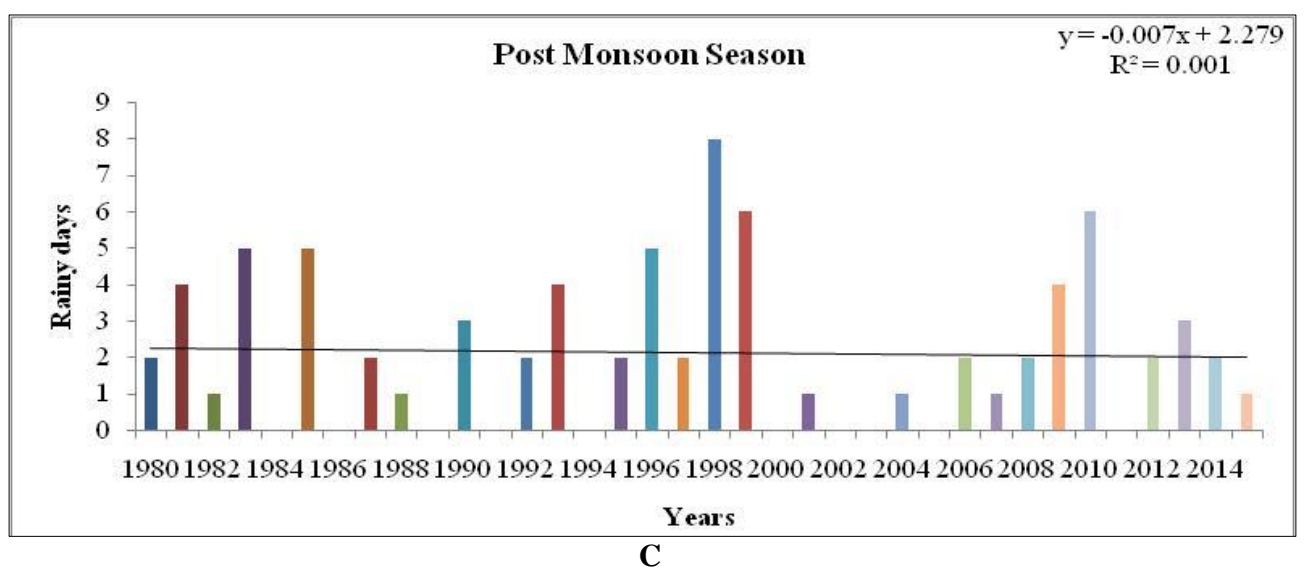

Fig 2A-C: Monthly and Post monsoon season variability and trend at Navsari district 


\section{Conclusion}

The standard weekly rainy days analysis of binomial distribution for monsoon season of Navsari on chi-square test on binomial distribution was found in SW 22 to 31, 33 and SW 35 to 39 and post monsoon in standard week (SW) 41 to 44 shows significant. The result also reveals that the monsoon season SW 32 and 34 and post monsoon season SW 40, 45, 46 and 47 revealed non-significant result. Analysis reveals the rainfall is not equally distributed during SW 32, 34, 40, 45, 16 and 47, so that the test of binomial distribution is a good fit. Monsoon season rainfall data of Navsari district reveals that the normal distribution at 10,20 and $30 \%$ probability levels for the month of June, July, August and September shows the possibility of increasing rainy days occurrence. The Navsari districts during post monsoon season rainfall of months of October and November reveals decreasing tendency. The binomial distribution fit only those standard weeks in which rainfall is not equally distributed. The frequency distribution is workout for monsoon (22 to 39 standard weeks) and post monsoon (40 to 47 standard weeks) seasons. From above results observed that the rainfall distribution is not equally distributed so test of binomial distribution at above given standard week is a good fit. On the basis of these finding the result reveals that during monsoon season favorable condition for agriculture crops was observed at Navsari district and the data also shows that decreasing tendency in rainfall was observed.

\section{References}

1. Basu GC, Bhattacharjee U, Ghosh R. Statistical analysis of rainfall distribution and trend of rainfall anomalies district wise during monsoon period over West Bangal. Mausam 2004;55;3:409-418.

2. Ben-Gai T, Bitan A, Manes A, Alpert P, Rubin S. Spatial and Temporal Changes in Rainfall Frequency Distribution Patterns in Israel. Theor. Appl. Climatol., 1998;61:177-190.

3. Chand R, Singh UP, Siddique LA, Kore PA. Analysis of weekly rainfall of different period during rainy season over safdajung airport of Delhi for $20^{\text {th }}$ century- A study on trend, decile and decadal analysis. Mausam 2011;62(2):197-204.

4. Guhathakurta P, Menon PA, Dikshit SK, Sable ST. Extreme rainfall of Andhra Pradesh using a probability distribution model: A regional estimate. Mausam 2005;56(4):785-794.

5. Jaswal AK, Rao GSP. Recent trends in meteorological parameters over Jummu and Kashmir. Mausam 2010;61(3):369-382.

6. Jaswal AK, Bhan SC, Karandikar AS, Gujar MK. Seasonal and annual rainfall trends in Himachal Pradesh during 1951-2005. Mausam 2015;66(2):247-264.

7. Joshi UR, Dube RK, Rao PGS. Trend in precipitation Extremes over India, National Climate Center Research Repost 2005, 3.

8. Kumar N, Patel SS, Chalodia AL, Vadaviya OU, Pandya HR, Pisal RR et al. Markov Chain and Incomplete Gamma distribution analysis of weekly rainfall over Navsari region of South Gujarat. Mausam 2015II;66(4):751-760.

9. Kumar N, Pisal RR, Shukla SP, Patel SS. Analysis of climatic variability at heavy rainfall zone of South Gujarat. Mausam 2015-I;66(40):850-856.

10. Kumar RK, Pant GB, Parthasarathy B, Sontakke NA. Spatial and subseasonal patterns of the long term trends of Indian summer monsoon rainfall. Internation $\mathrm{J}$. Climatology 1992;12:257-268.

11. Lettenmaier DP, Wood EF, Wallis JR. Hydroclimatological trends in the continental United States 1948-88. J. Clim 1994;7:586-607.

12. Lunagaria MM, Dabhi HP, Pandey V. Trend in the temperature and rainfall extremes during recent past in Gujarat. Journal of Agrometeorology 2015;17(1):118123.

13. Manikandan N, Rani BA, Satyamoorthi K. Weekly rainfall variability and probability analysis for Coimbatore in respect of crop planning. Mausam 2014;65(3):353-356.

14. Mohapatra M. Recent trends in climate of Banglore. Mausam 2002;54(4):425-438.

15. Ray K, Mohanty MNA, Chincholikar JR. Climate variability over Gujarat, India, ISPRS Archivers XXXVIII-8/W3 Workshop Proceedings: Impact of Climate change on Agriculture 2009.

16. Sahu DD. Text book of Agrometeorology and remote sensing principles and practices 2007, 43-44.

17. Seetharam K. Rainfall models-a study over Gangtok. Mausam 2010;61(2):225-228.

18. Sen Z, Eljadid AG. Rainfall distribution function for Libya and rainfall prediction. Hydrological Sciences Journal 1999;44(5):665-680. 